\title{
Status of small millets diseases in Uttarakhand
}

\section{- BIJENDER KUMAR}

Department of Plant Pathology, College of Agriculture, G.B. Pant University of Agriculture and Technology, Pantnagar UDHAM SINGH NAGAR (UTTARAKHAND) INDIA

\section{ARITCLE INFO}

Received : 27.10 .2015

Accepted : 15.03 .2016

\section{KEY WORDS :}

Small millets, Blast, Leaf blight, Cercospora leaf spot, Smut, Sheath blight
Corresponding author:

Email: bij1005@yahoo.co.in

\begin{abstract}
Although, small millets are known to cope up with abiotic and biotic stresses, nevertheless, under vulnerable conditions some of the diseases cause heavy losses and can damage entire crop. Therefore, the present investigation was planned with the objective to know the status of major diseases of small millets and also to observe occurrence of any new biotic problem with time in small millets. Based on the study conducted during 2007-2012, blast (Pyricularia grisea) and Cercospora leaf spot (Cercospora eleusinis) of finger millet, leaf blight (Helminthosporium monoceros) and grain smut (Ustilago panici-frumentacei) of barnyard millet, blast (Pyricularia setariae) and leaf blight (Cochliobolus setariae) of foxtail millet, leaf spot or blight (Bipolaris panici-miliacei) of proso millet diseases were found to be the major constraints in successful cultivation of small millets in Uttarakhand. However, in addition to these some of the diseases like; green ear or downy mildew (Sclerophthora macrospora) and foot rot or wilt (Sclerotium rolfsii) in finger millet, head smut (Ustilago crusgalli) and sheath blight (Rhizoctonia solani) in barnyard millet, smut (Ustilago crameri) in foxtail millet and sheath blight $(R$. solani) in proso millet have been recorded for the first time in Uttarakhand.
\end{abstract}

How to view point the article : Kumar, Bijender (2016). Status of small millets diseases in Uttarakhand. Internat. J. Plant Protec., 9(1) : 256-263. 